\title{
monet e a translinearidade em "le boulevard des < apu<ines"
}

\author{
Teresa Labarrère
}

Mestre em Artes-Cinema na ECA-USP

\begin{abstract}
Based on WoliTlin 's Visibilisin, the text deciphers Monet's Le Boulevard des Capacities as well as it throws ironically other ciphers, which break up like a prism the artistic paradigm of the nineteenth century'. Due to its emblematic strength, the picture represents the non plus ultra of the artistic and the cultural revolution which took place in Europe all through the past century.
\end{abstract}

KEY WORDS: Impressionismo - Translinearidade - Subjetividade.

Toda análise de uma obra de arte insere-se num modo de visão subjetivo e condicionado. Devido aos limites inerentes a toda c qualquer visão, somos conduzidos, inevitavelmente, a um juízo parcial, mas não por isso insuficiente, nem inverídico. Ao analisar Le Boulevarci cies Capucines, de Monet, não tenho a intenção, por certo, de fazer um corte epistemológico na obra - não pretendo, a partir da minha subjetividade, ter acesso à objetividade da obra; e sim, por meio desta, atingir uma outra subjetividade, que está para além da primeira.

Durante o império deNapoleão III, Haussmann construiu amplas avenidas no centro de Paris, denominadas bulevares. Pavimentados com macadame e medindo de $30 \mathrm{~m}$ a $100 \mathrm{~m}$ de largura, os bulevares foram construídos para "dar vazão aos fluxos mais intensos de tráfego e servir de principais ruas de comércio e wegóc/av'XBERMAN). 


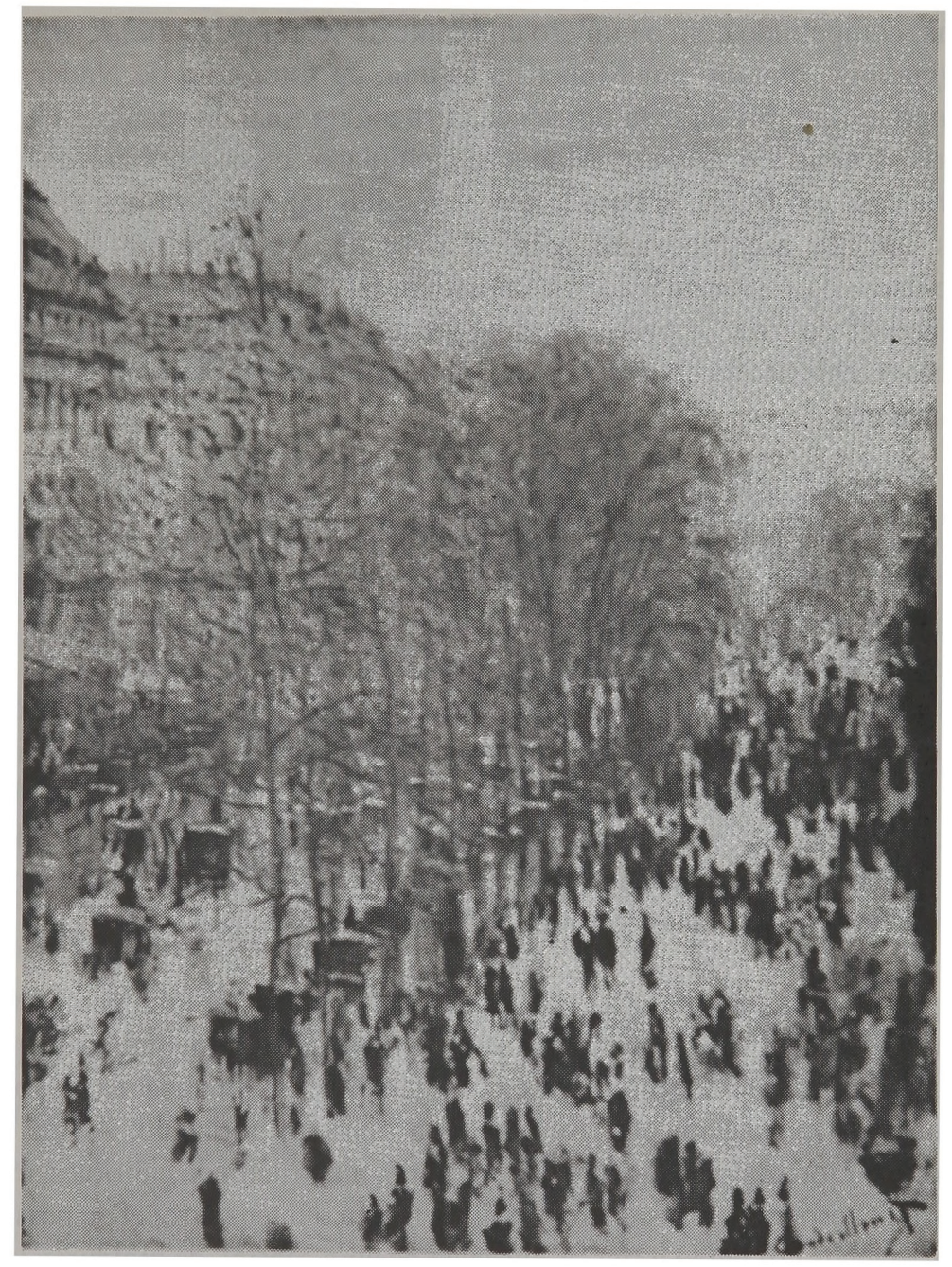

Claude Monet, Le Boulevard des Capucines (1873). New York, Collection Marshall Field. 
Todavia, não foi preciso muito tempo para que os bulevares também ficassem congestionados. Logo uma grande multidão aglomerava-se nas ruas, competindo com o número crescente de veículos. Le Boulevard des Capucines, pintado por Monet no estúdio de fotografia de Nadar, seu amigo íntimp, revela essa típica cena urbana do final do século XIX, em Paris. Como um flâneur, Monet contempla o intenso bulício da vida parisiense e o transpõe para a tela, numa linguagem de ritmos cromáticos, em que a composição, a luz e a cor não se encontram a serviço exclusivo da representação, mas possuem tal autonomia, que o conceito ocidental de arte, a partir do advento do Impressionismo, se afasta inexoravelmente do eixo greco-romano, para explorar os campos baldios adjacentes.

De imediato, o quadro destaca-se como uma composição de acentuado caráter pictórico (na acepção wolffliniana do termo). A paisagem apresenta uma coloração amarelo-âmbar que domina todo o conjunto da tela. Em nenhuma parte se nota o efeito de claro-escuro que convém ao classicismo da forma plástica; ao invés, o claro-escuro é substituído por descontínuas gradações tonais que dão vibração às massas de cor. A desvalorização das linhas afrouxa os contornos da figura e amplia seus limites - os transeuntes, os veículos, os edifícios, os ramos das árvores, tudo se evola na névoa. Reduzidos a massas de cor, os elementos perdem definição, de modo que não é possível falar de partes independentes nem coordenadas - é o efeito geral do conjunto que se impõe.

Embora tudo pareça estar igualmente distante, de uma perspectiva quase imperceptível, a sensação de espaço é marcada, principalmente, pela direção das árvores. Estas, dispostas diagonalmente, conduzem a visão até o fundo da paisagem, onde se insinua a linha do horizonte. Ao pé das árvores, reforçando a diagonal para o fündo, uma fileira de cabriolés, estacionada à espera de passageiros, contrasta com o intenso tropel de pessoas e carruagens cruzando a rua. A ausência de eixo central, de molduras laterais, de contraste de direções (ou seja, de linhas ortogonais) compõe um conjunto atectônico, de equilíbrio instável. A margem direita livre bem como o amplo recorte da margem esquerda sugerem que o conteúdo do quadro se expande para fora de suas bordas. Convém notar, no canto mediano direi- 
to, a presença (ou vestígio) de um indivíduo de cartola, que parece observar a paisagem da sacada de um edifício (assim como fazia o pintor, simultaneamente, de uma janela próxima).

Ou este seria tão-somente uma mancha preta? Para um fruidor do século XIX, ainda não habituado aos snapshots e alheio dos cortes cinematográficos, nada mais esdrúxulo do que um enquadramento desse tipo. Que dizer, então, do que nele está contido? Ao ser exibida publicamente, quando da primeira exposição impressionista, nesse mesmo estúdio em que fora concebida, a tela suscitou perplexidade e furor. Leroy, crítico do Le Charivari, reagiu sarcasticamente àqueles borrões, a que chamou "cuspidelas pretas"

A absoluta licenciosidade das linhas, ao confündir os limites do ser, projeta-o à categoria do possível, ou do provável, de modo que toda uma sorte de gente equívoca se mistura na rua: "quem" são essas manchas pretas? Seriam os ricos habits noirs ou simples trapeiros? A ausência de feições, de mãos, de quaisquer traços característicos ou expressivos, obscurece a identidade das figuras. Mas isto, absolutamente, não importa. Não é o indivíduo, e sim a multidão anônima, o tema central do quadro. Assim como Victor Hugo, que a representava como a heroína da epopéia moderna, ou como Baudelaire, que a via como um refúgio para o herói da cidade grande(BENJAMIN, 1989), Monet registra a importância histórica do fenômeno das massas, no exato instante em que perde a escala da figura humana.

Ao fundo do quadro, onde a linha do horizonte vacila em distinguir o céu e a terra, ambos representados com a mesma cor de âmbar, o sagrado e o profano, o divino e o humano parecem pertencer ao mesmo e único reino. Ou teria sido, porventura, o divino banido do reino humano? Numa paisagem nevoenta como esta, em meio à enigmática multidão, vejo, nitidamente, Baudelaire atravessar o bulevar, deixando seu halo caído sobre o macadame.

Caramba! Que suprema ironia da matéria que elude o espírito! De um borrão se deduz o humano, do humano se desdiz Baudelaire. A pro- 


\section{Teresa Labarrère}

pósito, que diria Hegel se tivesse vivido o bastante para contemplar essa sofismática tela? E se, tendo vivido ainda mais um século, pudesse flagrar os soberbos e ininteligíveis borrões de Pollock, para quem a Arte refuta o absoluto e afirma-se como mero fenômeno?

"Caspita!" - diria ele, para início de conversa. Se fosse italiano.

\section{Bibliografia}

BENJAMIN, Walter. (1989). Obras escolhidas. São Paulo, Brasiliense, V. III.

BERMAN, Marshall. Tudo que é sólido desmancha no ar. 